\title{
La Teología de la Liberación en Chile
}

\section{DAVID FERNÁNDEZ FERNÁNDEZ}

\section{INTRODUCCION}

Este artículo es un acercamiento a la teología de la liberación en Chile, tema sobre el cual profundizaremos más ampliamente en nuestra tesis doctoral: Historia de la Iglesia católica en Santiago de Chile desde el Concilio Vaticano II basta la actualidad: el testimonio oral como fuente.

Concretamente en estas líneas queremos plantear la complejidad de la teología de la liberación como.corriente de pensamiento y como acontecimiento histórico. La pregunta fundamental de la cual vamos a partir es: ¿qué es la teología de la liberación en Chile?

Para contestarla es preciso tener claro en primer lugar que no es lo mismo hablar de teología de la liberación (TdL) chilena, brasileña o centroamericana,por ejemplo. Cualquiera que indague un poco en este tema descubre que no se puede hablar de la TdL como de un bloque monolítico, uniforme, plenamente definido. Dentro de la TdL hay diversas corrientes. De ahí la falsedad y la falta de espíritu crítico de quienes escriben sobre la TdL metiéndolo todo en el mismo saco. La TdL es una corriente de pensamiento muy dinámica y heterogénea. No cabe en definiciones cerradas.

Un segundo punto a tener en cuenta es que no se puede hacer la historia de la Iglesia en América Latina en los últimos 20 años sin analizar en profundidad qué es la TdL, y para esto no es suficiente con hacer una enumeración de teólogos de la liberación. Si nos limitamos a hablar de los intelectuales que sistematizan esta teología de forma científica sólo estaríamos llegando a la punta del iceberg. Por eso la historia de la TdL necesita un esfuerzo de clarificación y profundización.

Nuestra propuesta es acercarnos a la visión que los propios teólogos de la liberación tienen de sí mismos como punto de partida para discernir qué queremos decir cuando decimos TdL. Para ello nuestra fuente principal va a ser el testimonio oral.

Entre finales de octubre y principios de diciembre de 1993 estuvimos en Santiago de Chile y recogimos 36 testimonios como base oral para nuestra tesis. De ellos hemos extraido los testimonios más interesantès para estudiar la TdL en Chile. El testimonio oral nos aporta datos que nos permiten complementar los testimonios escritos, y algunas veces, inçluso, nos hacen descubrir que haciendo historia solamente a partir de documentación escrita podemos no sólo no com- 
prender los hechos en su complejidad sino además plantear cuestiones o afirmaciones que no se corresponden con la realidad. Un ejemplo: J.J. Tamayo en su libro Para comprender la Teología de la Liberación (1) sitúa a Segundo Galilea, sacerdote chileno, como uno de los más destacados representantes de la TdL. Dialogando con Segundo Galilea en el Seminario Pontificio de Santiago de Chile, él nos decía:

"Mira, yo no me considero teólogo de la liberación. Trabajé el tema en su tiempo. Sobre todo algo el 70 . Tratando el carácter pastoral. No soy teólogo de la liberación porque no soy teólogo así, dedicado, profesional. Nunca he hecho clase de teología. Sé teología, creo que tengo cultura teológica pero no soy... de la TdL no he escrito nada. Escribí un folleto que puse al día después de Puebla y que fue bien recibido por moros y cristianos ino? Incluso crítico de ciertas corrientes de TdL. Yo nunca me sentí cómodo con la corriente, en ese entonces, principios de los 70 , predominante. Ya desde el 72 ya había muchas corrientes en América..." (2).

\section{¿QUÉ ES LA TEOLOGÍA DE LA LIBERACIÓN?}

Empecemos por Raúl Rosales. Raúl es un teólogo laico,católico, profesor del Instituto Alfonsiano de Teología y Pastoral, investigador y coordinador del CEDM (Centro Ecuménico Diego de Medellín). Tiene 37 años, está casado y es padre de 4 hijos.

Sobre la TdL escribe:

"Teología de la Liberación designa a aquella corriente dentro del cristianismo latinoamericano que ha intentado expresar una novedosa experiencia de fe de nuestro pueblo. Al interior de la tradición teológica cristiana del continente, esta teología tiene la pretensión de ser una nueva manera de pensar a Dios y todo lo relacionado con él. A partir del horizonte de la liberación se iluminan y ubican todas las cosas produciendo nuevos significados. Pero más aún, lo realmente significativo de esta teología es el hecho de que ha tomado en serio una pregunta urgente para las Iglesias del continente: ¿Cómo predicar al Dios de la vida en medio de la situación de miseria injusta en que vive la mayoría de la población del continente? Articular esta pregunta que parte de la experiencia de los cristianos en Latinoamérica con la Revelación de Dios a su Pueblo ha sido, pues, el principal afán de esta teología" (3).

Detengámonos brevemente. Para Raúl la clave de la TdL es un interrogante: cómo hablar del Dios de la vida en medio de una situación de miseria. La TdL es una teología situada que nace de una pregunta que surge en la experiencia coti-

(1) TAMAYO, Juan José: Para comprender la Teología de la Liberación. Estella, 1990, pp. 236-241.

(2) GALILEA, Segundo: Testimonio oral, 24/11/93. Santiago, Chile. El folleto al que se refiere se titula: La Teología de la Liberación después de Puebla. Bogotá, Colombia, 1979.

(3) ROSALES, Raúl: "Teología de la Liberación", en Breve Diccionario Teológico Latinoamericano de Raúl Rosales y José Manuel de Ferari (editores), Santiago, Chile, 1992, pág. 339. 
diana de los cristianos latinoamericanos. Así pues, lo primero es la práctica, la vivencia, el cuestionamiento, y luego, al llevar esa experiencia ante la Palabra de Dios empieza a articularse la teología, la respuesta desde la Revelación. De ahí brota algo novedoso: "una nueva manera de pensar a Dios y todo lo relacionado con él".

Ahora bien, la TdL ¿es sólo labor de los teólogos profesionales? ¿Quién es el sujeto de esta teología? Lo más conocido es la reflexión de los pensadores que escriben, y dentro de éstos unos son más conocidos que otros. Pero lo conocido no es habitualmente lo único, y a menudo ni siquiera es lo más importante. Sintetizando podríamos decir que habría dos formas de plantear la TdL como mínimo: como labor específica de teólogos o personas que hacen teología escrita en torno a un corpus más o menos definido de conceptos y con una metodología determinada; o como la reflexión teológica de todo cristiano inmerso en un contexto de miseria injusta que intenta descubrir la voluntad de Dios en la historia.En este caso praxis existencial y teológica del pueblo estarían muy vinculadas. Este segundo aspecto nos abre la perspectiva de un sujeto histórico del quehacer teológico latinoamericano desde el horizonte de la liberación mucho más amplio. Sobre este punto Raúl Rosales expone:

"Mira, yo creo que el punto es qué entiendes por TdL. Si entiendes tú un cuerpo de doctrinas absolutamente claras y definidas por Gustavo Gutiérrez desde el primer día y los demás... lo único que se ha hecho ha sido repetir ese cuerpo de doctrinas. Se creó una colección ¿no es cierto?. Son 50 volúmenes, bueno, salieron 25, pero la pretensión era constituir un cuerpo así de lo que piensa la TdL sobre la Virgen María, sobre Cristo, sobre la Iglesia, sobre todos los temas... La gente no ha hecho cursos de TdL en Chile tan sistemáticos. El Centro Diego de Medellín es una de las pocas instancias de TdL y estamos mirados con lupa por todo lo que hacemos; pero por otra parte, si consideramos que la TdL es un proceso de reflexión cristiana en general, todo cristiano tiene que hacerla, toda Iglesia que se precie de tal tiene que hacerla, esa reflexión teológica, es decir, dar razón de su fe en el presente. Descubrimos que hay 'TdL en la Iglesia chilena desde mucho tiempo atrás" (4).

Para hacer la historia de la TdL no sirven las visiones reduccionistas. El verdadero archivo es la base popular de la Iglesia. Las obras de los teólogos de la liberación son también fundamentales, pero siempre que hagamos una lectura de las mismas desde el contexto histórico y leyendo entre líneas para descubrir la propia trayectoria personal del que escribe y su vinculación con los procesos de liberación latinoameticanos. Decimos esto porque hay teólogos que hacen una teología vinculada a la vivencia del pueblo desde su propia experiencia de inserción, en cambio otros se han perdido en los vericuetos de una teología académica más orientada a la discusión con las otras tradiciones teológicas que a servir de instrumento cotidiano de liberación.

Recopilando lo dicho hasta ahora, la TdL es un ejercicio de búsqueda de la voluntad de Dios en la historia; historia que es sólo una. No existe una historia de

(4) ROSALES, Raúl: Testimonio oral, 16/11/93, Santiago, Chile. 
la salvación al margen de la historia profana. Sólo existe una historia y'en ella está Dios (5). De ahí la importancia de discernir los signos de los tiempos.

Otra cuestión es si la TdL es realmente una nueva forma de hacer teología o es sólo un tipo de teología pastoral. Las implicaciones de una u otra opción son importantes. Raúl Rosales apunta la novedad de la TdL y su intento de repensar toda la teología desde la perspectiva de la liberación. Sin embargo, para Segundo Galilea la TdL es sólo una teología sectorial. En el folleto que él mismo citaba anteriormente distingue tres maneras de hacer teología: teología como "sabiduría", que "procura hacer de la Palabra de Dios alimento real para la vida" y "no tiene una pretensión sistemática ni directamente 'científica'"; teología sistemática, "científica" o dogmática, que "procura el encuentro de la fe y de la razón humana en el estudio de la Revelación divina"; y una tercera forma que llama "teología pastoral" y cuyo punto de partida "es más bien la vida de la Iglesia, la acción pastoral, el compromiso de los cristianos, la realidad en la cual la Iglesia ejerce su misión" (6). Segundo Galilea sitúa la TdL en este último apartado. La TdL es para él una teología pastoral.

En cambio, los teólogos que se autodefinen teólogos de la liberación o se sienten cercanos a esta corriente teológica están con el planteamiento de Raúl Rosales. Eso explicaría la existencia de iniciativas como la colección "Teología y Liberación"o Mysterium liberationis, en las que se intenta rehacer toda la teología desde lo más hondo de la tradición cristiana pero en una perspectiva liberadora (7).

En esta línea, el teólogo granadino Jose María Castillo afirma lo siguiente:

“(..) la teología de la liberación no se presenta como un nuevo sector de la teología en general, es decir, de la misma manera que hay teología fundamental, teología dogmática, teología moral o teología pastoral; así ahora tendríamos un nuevo campo del quehacer teológico: teología de la liberación. No se trata de eso. La teología de la liberación no es un nuevo sector de la teología, sino un nuevo modo de hacer teología, ya sea en teología fundamental, en teología dogmática, en teología moral,etc,etc..." (8).

La TdL abarcaría las tres maneras de hacer teología que plantea Segundo Galilea: teología como "sabiduria", teología "científica" y teología pastoral. Tendría una expresión científica (teólogos profesionales), una expresión pastoral (militantes cristianos) y una expresión teológica como sabiduría popular, como teología del pueblo.

(5) ROSALES, Raúl; Testimonio oral, 16/11/93, Santiago Chile.

(6) GALILEA, Segundo: op. cit.

(7) "Teología y Liberación" era un proyecto de 50 libros sobre distintos temas de TdL. El proyecto fue bloqueado por el Vaticano antes de ser realizado en su totaliclad. Según Raúl Rosales sólo se publicaron unos 25 libros. Mysterium Liberationis. Conceptos fundamentales de la Teología de la Liberación, Madrid, 1990; es un libro cuya finalidad "Consiste en ofrecer de manera sistematizada lo central de la teologia de la liberación", según palabras de Jon Sobrino en la presentación del mismo. Este e Ignacio Ellacuría son los coordinadores de la obra, en la que también participan 35 teólogos y teólogas.

(8) CASTILLO, J.M.: El seguimiento de Jesüs, Salamanca,1992, pág. 165. 
Optar por una u otra visión no es sólo una cuestión teórica sino que implica una forma de mirar y entender la Iglesia, y por lo tanto su historia.

Sigamos ahora escuchando el testimonio de José Aldunate, sacerdote jesuita de 77 años, chileno, profesor de teología moral, que después de muchos años ejerciendo la teología académica experimentó un proceso de conversión bastante "decidor": (utilizando la expresión chilena) sobre lo que es la TdL:

"Después de cumplir ciertas tareas como maestro de novicios,me encomendaron "Mensaje (9) y el provinciarato después. Bueno, he sido siempre profesor de teología, pero en el fondo lo que me convenció mucho fue la 'TdL, y entonces quise emprender la teología no tanto desde un punto de vista más ideológico sino desde un punto de vista más vivencial, viviendo la condición obrera, poblacional (10) también. Y eso para mî ha sido muy rico, muy positivo poder pensar desde las situaciones reales más que desde!los principios o las teorias ¿no?. Y es la posición de alguna TdL" (11).

José Aldunate se hizo cura obrero pasados los 50 años. Luchó contra la dictadura a través del Movimiento contra la Tortura "Sebastián Acevedo" (12). Se vinculó definitivamente al mundo obrero y poblacional. Dos ideas importantes: "don Pepe", como se le conoce afectivamente, opta por hacer teología desde "las situaciones reales", desde la vida, y la vida del pueblo chileno durante la dictadura eśtá marcada por la miseria, la cesantía, la represión, la tortura; los detenidosdesaparecidos; en pocas palabras, el cautiverio y la muerte de los más pobres y de los que resisten al régimen militar. La segunda idea es que ésta es "la posición de alguna TdL". Al hablar de TdL habla en plural. Hay distintas corrientes de TdL. Y no todos los que hacen TdL la hacen desde la encarnación en las realidades de miseria. Más adelante veremos un intento de clasificación de la TdL en Chile y entederemos la diversidad de lugares desde donde se construye la TdL, o mejor dicho, quizás, las teologías de la liberación.

Demos un paso más en nuestro análisis. ¿Cómo ha influido la TdL en Chile?

"Yo creo que ha influido tanto que ha sido asimilada y que hoy día no hace falta hablar como que fuera un cuerpo de ideas que llegan sino que ha sido, es connatural yo creo a las comunidades de base la TdL y ha entrado muchio en el episcopado. Por ejemplo, esa forma de reflexionar que tienen, que ho es exclusivamente de la TdL, viene de antes, de ver-juzgar-actuar,es un poco todo el método de la TdL, viene a ser eso,partir de las situaciones y de ahí llegar a reflexionar sobre el significado que tiene todo eso. No partir

(9) "Mensaje" es una revista publicada por los jesuitas en Chile.

(10) Los barrios marginales, periféricos reciben en Chile el nombre de poblaciones. Sus habitantes son los pobladores.

(11) ALDUNATE, José: Testimonio oral, 25/11/93, Santiago, Chile.

(12) El Movimiento contra la tortura "Sebastián Acevedo" recibe ese nombre en recuerdo de Sebastián Acevedo, quien se prendió fuego delante de la catedral de Concepción como protesta para que la CNI (Central Nacional de Información) dejara de torturar a su hijo y a su hija. 
de conceptos, de principios abstractos universales que sirven para todo el mundo.Yo creo que eso está muy asimilado, y eso es muy importante" (13).

Como dice José Aldunate el método ver-juzgar-actuar no es exclusivo de la TdL. Fue extendido por la Acción Católica. Entonces, si el método es el mismo, ¿cuál es la diferencia?. De hecho la Acción Católica creció bajo el amparo y el empuje de la jerarquía, sin embargo la TdL ha tenido muchos problemas con la Iglesia jerárquica en su conjunto, salvando excepciones a nivel personal. La clave puede estar en la forma de "ver" y en la forma de "acturar". En la TdL el "ver" se convierte a menudo en un "vivir", es decir, ver las realidades de miseria y opresión desde dentro de esa realidad. No es sólo mirar de paso, sino encarnarse en esa realidad. La mirada es entonces diferente y la acción es mucho más radical. La TdL va a surgir precisamente de grupos de Acción Católica especializados que empiezan a hacer la experiencia de acercarse a los barrios marginales.

Jaime Escobar es uno de los más entusiastas divulgadores de la TdL en Chile. Es laico, tiene estudios de economía y teología, y se dedica a animar, asistir y acompañar comunidades de base.

"La TdL para nosotros ha sido el elemento más que motivador de descubrir incluso nuestra espiritualidad liberadora. Nosotros hemos ido caminando, estudiando, como leyendo, compartiendo a la luz de la TdL. Nosotros, claro, tomamos el Evangelio por sobre todas las cosas (...). Evidentemente que si no hubiera existido este pensamiento, esta producción teológica, nosotros andariamos con la brújula muy perdida (...)" (14).

Para Jaime la TdL ha influido mucho en Chile y "ha sido un elemento determinante para los laicos" (15). Tras el Concilio Vaticano II el laico adquiere un rol más importante en la Iglesia católica. Rol que en muchos aspectos se ha quedado en los papeles, puesto que en la práctica sigue siendo un ciudadano de segunda clase dentro de una Iglesia-institución profundamente marcada por la clericalización. La TdL es, entonces, una apertura de lo teológico hacia el laico. El laico no es sólo objeto sino también sujeto del quehacer teológico. La teología deja de ser un monopolio del clero. De esta forma "los miembros de las Comunidades Eclesiales de Base, con Biblia en mano y sabiéndola leer en su contexto real de miseria, opresión y dolor, son peritos, saben lo que es ser cristianos, pueden dialogar con sacerdotes, con obispos, y con el mismo Papa" (16).

Ahora bien, dependiendo del lugar donde esté situado o la opción que tome así será la forma de mirar y actuar del laico. Nos interesa el laico pobre, excluido,

(13) ALDUNATE, José: Testimonio oral, 25/11/93, Santiago, Chile.

(14) ESCOBAR, Jaime: Testimonio oral, 21/11/93, Santiago, Chile.

(15) Ibidem.

(16) DUSSEL, Enrique: “Teología del laicado?", en "Hacia una nueva teología del laicado”, Fe y Solidaridad $n^{2}$ 63, ECO, Santiago, Chile, 1988, pp. 5-12.

Es un articulo muy interesante sobre el papel que se le ha asignado históricamente al laico en la Iglesia y sobre qué significa realmente ser laico en una Iglesia Pueblo de Dios. 
marginado y el laico que sin serlo opta vitalmente por un mundo donde no exista la desigualdad. la injusticia, la miseria. Desde esta segunda perspeciva nos habla Jaime Escobar. Para él el método de la TdL es tan sencillo "que hasta un niño lo entiende", porque "¿dónde está usted?, ¿está en la universidad?, ¿está en Las Condes, en uno de los sectores más ricos de Chile?, ¿está en una población popular?, ¿đónde está usted?. Aquí. ¿Qué ve usted ahí?. Veo esto,esto...Se supone que estamos entre cristianos. Juzgue usted a la luz del Evangelio. No a la luz de la TdL. Del Evangelio. Vamos a Marcos, vamos a Juan. Vamos a las Epístolas. Vamos a los Salmos. Tengamos un rato de oración. Este ver èse compadece con lo que nos pide el Evangelio? Con el discernimiento que salga de la lectura,de la oración, actuémos entonces en consecuencia. Y ahí entra la TdL.En esa praxis entra la TdL" (17).

Jaime hace hincapié en la relación entre TdL y acción del laico. Reafirma la importancia del rol del laico no sólo a nivel sociopolítico sino también al interior de la iglesia: "La iglesia somos nosotros" (18). Rompe con cualquier visión clerocéntrica. Además, destaca el papel central del Evangelio en la TdL.

Ronaldo Muñoz, sacerdote chileno que pertenece a la congregación de los Sagrados Corazones, es el teólogo más representativo e "internacional" de la TdL chilena. Es profesor del Instituto Alfonsiano de Teología y Pastoral y director de la revista Pastoral Popular. Vive desde hace años en poblaciones de la periferia de Santiago. Actualmente está en Yungay, población de la zona sur. Tiene 61 años. En la presentación de su libro Dios de los cristianos, el editor lo caracteriza como "un tipo raro de teólogo, que une ciencia, mística, finura y profunda empatía" (19). Nos parece importante también traer a colación un pequeño fragmento del prólogo de su tesis doctoral escrito por Bernardino Piñera, obispo de Temuco en ese momento. En él Ronaldo es captado en lo más genuino y dinámico de su ser. Nos interesa porque define lo que quiere ser la TdL:

"Ronaldo Muñoz es teólogo,es decir, que dedica su vida a pensar en las cosas de Dios. Busca a Dios preferentemente entre los hombres, va rastreando sus huellas, no sólo en los libros y en las revistas, sino en los barrios obreros, en las reuniones estudiantiles, en medio del rumor de la vida o de la violencia política. Piensa a medida que va viviendo y vive, de acuerdo con lo que va pensando, con una senciliez tensa, una autenticidad angustiada que denotan, a la vez, lo difícil de su intento y el total compromiso con la tarea" (20).

La cita es bastante elocuente. No necesita comentarios. La labor teológica de Ronaldo surge, intenta surgir, de las entrañas de su pueblo; recoge su tradición de lucha cotidiana por la vida, su sentido de la solidaridad, el sufrimiento que le golpea desde hace años y sus ansias de liberación y fiesta. La alegria como atributo del Dios de Jesús que escucha el clamor de su pueblo y opta por la liberación frente al cautiverio. La alegría de un pueblo que descubre la misericordia de Dios.

(17) ESCOBAR, Jaime: Testimonio oral, 21/11/93, Santiago, Chile.

(18) Ibidem.

(19) MUÑOZ, Ronaldo; Dios dé los cristianos, Madrid, 1987.

(20) MUÑOZ, Ronaldo: Nueva conciencia de la iglesia en América Latina, Salamanca, 1974, pág. 9. 
"Nuestra palabra misericordia -que es una voz latina- quiere traducir una voz hebrea bíblica, que hace referencia no al corazón sino al útero materno. Es la conmoción de las entrañas de la madre por el sufrimiento injusto de su criatura inocente. Es como lo que hemos escuchado en algunos relatos de tortura, lo que siente una madre cuando oye a su hijo gritar porque está siendo torturado. No es algo de la cabeza, ni siquiera del corazón; la Biblia dice que eso viene del útero, del vientre de la madre. (..) la misericordia es el atributo soberano de Dios, por encima del poder. Más que todopoderoso, nuestro Dios, el de Jesucristo, es sobre todo misericordioso y eso significa que la imagen más radicalmente bíblica de Dios es una imagen materna, no paterna" (21).

El testimonio de Ronaldo nos introduce en la problemática que ha surgido desde el principio en torno a la TdL, problemática que nos muestra cómo ha sido percibida dicha teología latinoamericana desde Europa. Hasta el Concilio Vaticano II la teología que se conocía en América Latina era una teología importada de Europa. Tras el Concilio los teólogos latinoamericanos empiezan a tomar conciencia de que igual que existe una dependencia económica respecto a Europa, existe también un dependencia teológica. En esos años previos a Medellín (1968) empieza a despertar una teología auténticamente latino-americana, autónoma. Esta es una de las características fundamentales de la TdL y lo que explicaría los recelos por parte de Roma ante una teología que rompe el monopolio teológico eurocéntrico.

"Parece que es considerado peligroso para la unidad y la cohesión interna de la Iglesia católica el que haya teologías que no puedan ser controladas de cerca por el gobierno central de la Iglesia, porque los problemas son otros, los horizontes son otros, las preguntas son otras y porque no sólo están dando, ofreciendo tesis alternativas frente a temas puntuales de la teología moral o bíblica sino que implica esto una nueva manera de hacer teología, de leer el evangelio, de actualizar la tradición viviente de la Iglesia en relación con la vida de la gente, con la cultura de la gente..." (22).

Uno de los puntos de conflicto entre TdL y Roma, el más importante según Ronaldo, es la lectura de la Biblia por parte del pueblo. Antes hablamos del nuevo rol del laico en la iglesia tras el Vaticano II. Pues bien, que el pueblo asuma este rol con seriedad y responsabilidad implica un profundo discernimiento de la realidad a partir de la la Palabra de Dios, un vincular de verdad la vida y la Palabra. Esto se da de forma muy especial en las comunidades de base. Al irrumpir el pobre en la Biblia, en la teología, quedan desenmascaradas las alianzas históricas de la Iglesia oficial con el poder.

(21) Entrevista a Ronaldo Muñoz que forma parte del libro De Lonquén a los Andes, Santiago, Chile, 1993, donde se recogen ocho testimonios sobre los últimos 20 años de la Iglesia católica chilena.

(22) MUÑOZ, Ronaldo: Testimonio oral, 1/12/93, Santiago, Chile. 
Uno de los últimos detonantes de esta tensión fue el proyecto "Palabra-Vida" (23) elaborado por la CLAR (Conferencia Latinoamericana de Religiosos). Este conflicto nos revela dos puntos importantes: el miedo del Vaticano ante la lectura bíblica por parte del pueblo y el papel tan importante que han jugado los religiosos y religiosas de América Latina en el desarrollo de una teología latinoamericana liberadora.

Concretamente en Chile, las religiosas hicieron en Santiago una pastoral de frontera en las poblaciones más periféricas y desarticuladas en los años 60 que abrieron camino para una inserción real de los miembros "consagrados" de la Iglesia en la vida del pueblo. Como relata Francisca Morales, religiosa chilena de la congregación del Amor Misericordioso, "en ese año (1967) el Cardenal Silva nos había pedido que nosotros abriéramos casas, viviendas en medio de la gente, en sectores del Santiago más marginal, donde no había sacerdotes ni presencia oficial de iglesia" (24).

\section{INTENTO DE CLASIFICACIÓN DE LA TdL EN CHILE}

Como decíamos al principio, la TdL no es un bloque monolítico. Somos conscientes que cualquier intento de clasificación puede ser parcial dependiendo de los criterios que utilicemos, puesto que destacaremos unos aspectos y posiblemente desatenderemos otros. De todas formas creemos que una clasificación puede ser útil para entender la diversidad y la complejidad de una relidad, en este caso la TdL. Es por eso que vamos a sugerir un intento de clasificación, no tanto por encerrar la TdL en un esquema totalizante, como para que nos sirva para comprender el fenómeno en su fecunda pluralidad. Para ello vamos a contrastar las intentos de clasificación que los propios teólogos chilenos dan de la TdL.

Ronaldo nos habla de cuatro filones (esta misma palabra, filones, nos dice mucho del carácter abierto de esta tipología) "que dice una relación con distintos lugares sociales, o espacios, o instancias de la teología" (25):

(23) Sobre el conflicto Vaticano- ClAR en torno al proyecto "Palabra-Vida" puede consultarse el libro de Giulio Girardi: El templo condena el Evangelio.El conflicto sobre la teología de la liberación entre el Vaticano y la CLAR, Madrid, 1994.

En este libro, en las pp. 97-117, queda recogido el documento de la CLAR sobre el proyecto "Palabra-Vida", cuyo objetivo general es "alimentar la Vida con la Palabra de Dios, leíd'a desde los pobrés, para una 'Movilización' de la Vida Religiosa Latinoamericana, hacia una nueva Evangelización". Un punto fundamental del proyecto es que "la Biblia podrá llegar a las manos de los pobres y transformarse en Palabra Viva en el corazón del Pueblo (Puebla 380) para realizar el Reino".

(24) MORALES, Francisca: Testimonio oral, 4/12/93, Santiago, Chile.

Francisca Morales es una de las pocas mujeres chilenas que ha penetrado en el mundo de la teología rompiendo el monopolió masculino. A ella misma le resultó difícil nombrar a teólogas chilenas cuando le preguntamos por el papel de la mujer en la teología. Un ejemplo de esta invisiblidad de la mujer en el campo de la producción teológica es que de las 24 personas que escriben en el Breve Diccionario Teológico Iatinoamericano editado por Rehue (editorial del Centro Ecuménico Diego de Medellín), sólo una es mujer, Isabel Donoso. De todas formas creemos que el papel de las mujeres en el quehacer teológico cotidiano es fundamental, aunque no "figuten" como teólogas de la liberación ni escriban mucho. Chile tiene una cultura oral muy importante, de ahí la necesidad de no hacer esta historia sólo a partir de documentación escrita, pues de ser así la historia de la mujer acabaría perdiéndose como ha sucedido hasta ahora.

(25) MUNOZ, Ronaldo: Testimonio oral, 1/12/93, Santiago, Chile. 
1) Teología ligada a la actividad académica: destacarían Sergio Silva sscc, con su discurso sobre la cultura y la modernidad; Beltrán Villegas sscc, en teología bíblica; Pepe Aldunate en su vertiente más académica; Antonio Bentué,español, y Juan Noemi, teólogos laicos muy importantes...

2) Teología ligada a la práctica pastoral en la línea de la renovación parroquial: comunidades de base, protagonismo de los laicos en las bases populares, renovación misionera de la iglesia...En este filón se ubica el propio Ronaldo, y destaca a gente como Ignacio Vergara sj, pionero en esta línea "que trabajó el ecumenismo a nivel popular, la lectura popular de la Biblia, la renovación litúrgica a nivel popular", la experiencia de los círculos bíblicos, antecedente de las comunidades de base, y "la experiencia del trabajo,del mundo del trabajo; la entrada de sacerdotes como intelectual quiero decir, no sólo como pastor, sino como hombre que piensa, que reflexiona, que elabora discurso y que escribe también, en el mundo obrero"; y a Roberto Lebegue, sacerdote francés que estuvo muchos años en Santiago y que tuvo un papel muy importante en el Sínodo de la Iglesia de Santiago de 1967.

3) Filón que tiene como central el eje fe-política, Iglesia-sociedad, ligado a la experiencia de comunidades de base pero también en un sentido más amplio. El teólogo más representativo es Fernando Castillo. Aquí se incluye el diálogo entre el marxismo y el cristianismo.

4) Vertiente del cristianismo popular y de la historia en perspectiva popular, de "la historia hecha memoria, o rescatada, o releida en la perspectiva de los pobres". En este campo destacan Diego Irarrázaval y Maximiliano Salinas (26).

Respecto a esta tipología de Ronaldo en 4 filones tuvimos la oportunidad de dialogar con Sergio Silva y Max Salinas. A éste le pareció más o menos acertada. Sergio Silva puso la pega de que se mezclaban diferentes criterios yuxtapuestos: por un lado el lugar desde donde se hacía la reflexión teológica y por otro una cuestión más bien temática (los puntos 1 y 2 de la tipología de Ronaldo responderían al primer criterio; los puntos 3 y 4 , al segundo). Ahora bien, si el criterio es el lugar desde donde se hace teología, él sólo nombraría tres espacios: universidad, medio popular (comunidades de base) y centros como el Centro Ecuménico Diego de Medellín, es decir, ONGs.

Hay que apuntar que estas clasificaciones pueden sernos válidas para los últimos 15 años de la historia de Chile, pero no abarca lo anterior con claridad. Por ejemplo, queda fuera la línea de Pablo Richard y Hugo Assmann en los años 70 , donde la praxis de los grupos revolucionarios es fundamental (27).

(26) MUÑOZ, Ronaldo; Ibidem.

(27) Para J.C. Scannone, teólogo argentino, esta corriente que se desarrolló en los años $70 \mathrm{y}$ cuyos principales representantes son el chileno Pablo Richard y el brasileño Hugo Assmann es la vertiente más extrema de la TdL: "reflexionan teológicamente sobre la praxis de grupos cristianos politizados, radicalizados y comprometidos en la acción revolucionaria (no necesariamente violenta) en relación dialéctica con esa misma praxis", según palabras de J.B. Libanio haciendo referencia a la tipología que Scannone hace de la TdL, en Teología de la Liberación. Guía didáctica para su estudio, Santander, 1989, pág. 254. Scannone la acusa de elitismo y del peligro de convertirse en un "mero lenguaje sociológico cristiano, al servicio de la lucha de clases ", en palabras de J.J. Tamayo, quien considera que la crítica de Scannone es reduccionista y nada objetiva. Ver: Para comprender la Teología de la Liberación de J.J. Tamayo, Estella, 1990, pág. 128. 
Además, no aluden explícitamente al papel tan importante que tiene el tema de los derechos humanos en Chile tras el golpe de estado de 1973. La defensa de los derechos humanos va a estar presente en el quehacer cotidiano de la iglesia chilena y en su reflexión teológica (28). Ni tampoco a la teología cuyo sujeto es directamente, sin intermediarios, la mujer o el mundo indigena; fiel reflejo del carácter marginal de estos sectores de la sociedad.

Una clasificación más amplia y que alude a conceptos que vimos al principio es la de Pablo Richard, teólogo chileno que tuvo que exiliarse después del golpe de estado de 1973. Ha proseguido su actividad en Costa Rica, vinculado al DEI (Departamento Ecuménico de Investigaciones) y a CEHILA (Comisión de Estudios de Historia de la Iglesia en América Latina). También es asesor de comunidades de base y profesor de teología en la Universidad Nacional de Costa Rica. Pablo Richard utiliza un criterio evolutivo: "Al estudiar la relación entre la TdL y las prácticas, organizaciones y movimientos liberadores, el teólogo chileno distingue tres tipos de TdL, como tres momentos de un proceso evolutivo. Nace como teología espiritual en la práctica de la liberación de los pobres y oprimidos y desarrollada como teología en las CEBs (29), y madura como teología universal y liberadora en diálogo fecundo con la ciencia teológica académica y profesional" (30). De nuevo vemos la idea de que la TdL nació en la práctica de la liberación. En un segundo momento se hace orgánica a las CEBs, es decir, empieza a tomar una forma más sistemática,siempre vinculada a la experiencia de lucha contra la opresión, articulando teológicamente la vida de la CEBs. Y en un tercer momento, "madura" como teología universal en un plano más académico. Un ejemplo "decidor" es el título de uno de los trabajos de Pablo Richard que data de 1973: "Reflexión teológica en la lucha del pueblo".

\section{CRISTIANISMO Y MARXISMO EN CHIIE}

Uno de los aspectos de la TdL en los que se ha derrochado bastantes palabras ha sido el que hace referencia a su relación con el marxismo. Chile es un campo de estudio fundamental sobre la relación entre cristianismo y marxismo. El diálogo, o intentos de diálogo, entre ambos es anterior a la "existencia" de la TdL como tal. Fue fruto de la apertura del Concilio Vaticano II. Además, el diálogo no es sólo algo teórico. En Chile ese diálogo se dio en las poblaciones marginales a partir de la experiencia de lucha de los pobladores por sus derechos; pobladores, marxistas y no marxistas, cristianos y no cristianos, aunando sus fuerzas para conseguir un objetivo común. Después, a principios de los 70 , el ambiente de ideologización exagerada polarizó el mundo obrero y poblacional, pero las contradicciones eran por cuestiones políticas y no de fe. Había cristianos que eran de izquierda: socialistas, comunistas, miristas, del MAPU (31)... Incluso surge un par-

(28) Para este tema puede consultarse la obra: Los derechos bumanos y la Iglesia chilena de José Aldunate, Fernando Castillo y Joaquín Silva S., Santiago, Chile, 1983.

(29) Comunidades eclesiales de base.

(30) LIBANIO, Joao Batista: op. cit., pp. 255-256.

(31) Miristas: militantes del MIR, Movimiento de Izquierda Revolucionaria. El MAPU, Movimiento de Acción Popular Unitaria, nació de una ruptura de la Democracia Cristiana chilena. 
tido que se llamó Izquierda Cristiana. El testimonio de José Aguilera (32) ilustra lo que decimos:

"(...) llegó a ser un partido muy importante (MAPU), que fue uno de los partidos que recogió mucha de la gente cristiana comprometida en la acción social y en la acción sindical. Con todas las dificultades que suponía, ¿no es cierto?, el que cristianos, y sobre todo trabajadores, se incorporaran en partidos que no se definieran cristianos, que no tuvieran una definición doctrinal cristiana. Algunos tuvimos unas dificultades bastante complicadas por esto, pero fue también un descubrimiento bastante distinto. Nosotros habiamos optado en toda nuestra experiencia cristiana, trabajando mucho con la Biblia, trabajando mucho, intentando con el Evangelio unir la vida y la fe, y, de repente, nos encontramos en los partidos políticos que los partidos politicos tenían instrumentos de análisis de tipo sociológico, diferentes a los que se utilizaban en la iglesia, por supuesto, y en la experiencia política aparecían también los métodos de análisis marxistas y los métodos de análisis no marxistas. Entonces, había un conjunto de métodos de análisis de la realidad que aparecían ahí y que nosotros no teníamos mucha experiencia en eso (...). Fue un descubrimiento muy importante" (33).

La relación de cristianos y marxistas en la vida cotidiana ha sido muy importante. El diálogo práctico entre cristianismo y marxismo era más fecundo y tenía menos bloqueos ortodoxos que el diálogo teórico.

Ahora bien, ¿en qué medida, en qué aspectos está presente el marxismo en la TdL chilena?. Antes de 1973 podemos hablar de una opción por el socialismo por parte de sectores cristianos. Tras el fracaso del proyecto democratacristiano hay una radicalización política de los cristianos, sobre todo en sectores universitarios y parte del clero. Es aquí donde se da una reflexión más teórica sobre la opción por el socialismo, y más concretamente sobre la opción por el proyecto político de la Unidad Popular. Estos años, 1968-1973, viven una intensificación de la reflexión sobre la relación cristianismo-marxismo. Pero, ¿qué marxismo?. La teología de la liberación niega el "materialismo dialéctico"; "a Marx se le acepta y asume en cuanto crítico social" (34). Este punto es muy importante.

Para los que parten de una visión monolítica del marxismo como una ideología atea y materialista, el diálogo cristianismo-marxismo es absolutamente inviable. Y

(32) José Aguilera es en estos momentos secretario ejecutivo de la vicaría de pastoral obrera de la arquidiócesis de Santiago. Nació hace 61 años, está casado y tiene 4 hijos. Es sastre. Desde muy pronto se implicó en las luchas obreras y poblacionales de su pueblo. Es uno de los fundadores del MOAC (Movimiento Obrero de Acción Católica) en Chile. Fue coordinador del MOAC para América Latina y miembro del consejo del Movimiento Internacional de Trabajadores Cristianos, movimiento del cual fue presidente desde 1970 a 1974. Formó parte de la comisión que trabajó el documento "Paz" de la CELAM de Medellín (1968), junto a Gustavo Gutierrez, Don Helder Camara, el padre Arrupe y Pierre Bigó, entre otros.

(33) AGUILERA, José: Testimonio oral, 15/11/93, Santiago, Chile.

(34) DUSSEL, E.; "Teología de la liberación y marxismo", en Mysterium Liberationis. Conceptos fundamentales de la teología de la liberación, de Ignacio Ellacuría y Jon Sobrino (coordinadores), tomo I, Madrid, 1990, pág. 124. 
qué decir de un cristiano con una opción política marxista. Para los detractores de la TdL hablar de marxismo es hablar de estalinismo o algo peor. No ven otra posibilidad porque "la 'ideología' del orden establecido (que se lo confunde con el orden natural y divino) sitúa como lo maligno mismo, 'como el mal de los maniqueos, como el enemigo de (Cristo y del ejército) al 'comunismo' (término que incluye igualmente la acción profética, crítica y liberadora de la Iglesia y los cristianos)" (35).

Pero los teólogos de la liberación utilizan fundamentalmente la crítica social del maxxismo hacia la sociedad capitalista, se adentran en las ciencias sociales de carácter crítico para poder hacer una lectura de la Palabra de Dios desde la realidad de miseria y opresión que vive la mayoría del pueblo latinoamericano. Para situarse en la realidad ya vimos cómo hay un proceso de inserción en los medios populares. Ahora bien, al llevar esa realidad a la reflexión era necesario utilizar el análisis científico social. Los conceptos filosóficos no eran suficientes. De ahí que lo que más influyó en la TdL "fue el marxismo sociológico y económico latinoamericano de la 'dependencia"' (36), con toda su crítica al desarrollismo (37). Esto se puede apreciar en la documentación del Movimiento Cristianos por el Socialismo. En abril de 1971, 80 sacerdotes hicieron una declaración pública sobre la participción de los cristianos en la construcción del socialismo en Chile: en ella, frente a la opresión capitalista, optan por el socialismo como forma de construir una sociedad más solidaria y fraterna. En el texto aluden a la relación entre marxistas y cristianos:

"Todavía queda un largo camino que, recorrer, pero la evolución que se ha realizado en medios marxistas y cristianos permite hoy una acción común por el proyecto histórico que el país se ha dado.

Esta colaboración: será facilitada por un lado, en la medida en que el marxismo se presenta cada vez más como un instrumento de análisis y transformación de la sociedad, y por otro, en la medida en que los cristianos vayamos depurando nuestra fe de todo aquello que nos impida asumir un compromiso real y eficaz" (38).

(35) DUSSEL, E.; "Historia de la fe cristiana y cambio social en América Latina" en Fe cristiana y cambio social en América Latina de Instituto Fe y Secularidad, Salamanca, 1973, pág. 93. Este libro recoge las ponencias del "Encuentro del Escorial", realizado en Madrid en 1972.

(36) DUSSEL, E.; op. cit. ("TdL y marxismo..."), pág. 125.

(37) Nombre que recibe la postura de aquellos que creían que el subdesarrollo de América Latina era sólo una fase anterior al desarrollo y que con las inversiones adecuadas era posible alcanzar por evolución el tan deseado desarrollo.

(38) RICHARD, Pablo: Cristianos por el socialismo. Historia y documentación, Salamanca, 1976, pág. 213.

El grupo de "los 80" fue el germen del movimiento Cristianos por el Socialismo. Se ha escrito mucho sobre la relación entre CpS y la TdL, a menudo confundiéndolos como una misma realidad $y$ aprovechando esa identificación para acusar de marxista a la TdL. Sobre este aspecto profundizaremos en nuestra tesis doctoral y desenmascararemos la manipulación ideológica que ha sufrido este tema por parte de aquellos a los que no les interesaba el desarrollo de un pensamiento y un movimiento autónomos de liberación en América Latina. No es lo mismo TdL y CpS. Además, en Chile, antes de 1973, no se puede hablar con propiedad de TdL; de ahí también que prefiramos hablar de relación cristianismo-marxismo, que de relación TdL-marxismo, aunque aludamos a veves a la TdL, sobre todo cuando las fuentes lo hacen. Pero, como hemos dicho, antes de 1973 no es muy común. 
O sea, el marxismo como "instrumento de análisis y transformación de la sociedad".

Además, hay otro dato muy importante: "en algunos países de América Latina -y especialmente en Chile- el marxismo es parte de la cultura política del pueblo. No es un marxismo teórico-analítico, sino presente en las orientaciones socialistas profundamente arraigadas en los sectores populares" (39). El marxismo ha jugado un papel muy importante en la historia del movimiento obrero chileno. $\mathrm{Y}$, lógicamente, en un continente con un alto grado de religiosidad popular como América Latina, no cabe pensar que todos los obreros fueran ateos, o que no hubiera contacto entre obreros cristianos y no cristianos. Si antes de 1973 la opcción tenía tintes más partidistas, después del golpe de estado, "la opción socialista no aparece tan marcadamente referida a una 'ideología'. No se trata de adherirse al socialismo como algo exclusivamente predefinido por el 'marxismo-leninismo', sino al socialismo en cuanto se va gestando como "proyecto popular"' (40).

La equiparación $\mathrm{TdL}=$ marxismo peca de simplismo. Es una identificación más estratégica que científica, por parte de aquellos que quieren combatir la TdL (41). Puede decirse que hay teólogos que asumen la racionalidad marxista en su totalidad, pero son la excepción y no la regla. Lo más común es asumir el marxismo en cuanto crítica social del capitalismo, ya sea a nivel de TdL o de cristianismo del pueblo; pueblo en cuyo seno el proyecto de una sociedad mejor, que acabe con las desigualdades y la injusticia del capitalismo, tiene cabida como legado histórico de las luchas populares del pasado, en las que el marxismo estuvo presente de diversas formas.

\section{TEOLOGÍA DE LA LIBERACIÓN Y RELIGIOSIDAD POPULAR}

Un último aspecto que queremos abordar en esta aproximación a la TdL en Chile es cómo ha abordado ésta la religiosidad popular. Cómo ha sabido o no ha sabido ser cauce teológico de la sabiduría religiosa del pueblo.

Para ello partimos del testimonio de Maximiliano Salinas, teólogo laico, chileno, nacido en 1952. Es especialista en historia del cristianismo latinoamericano y miembro de CEHILA. Respecto a la TdL y a los teólogos de la liberación Max Salinas comenta:

"Quizás, yo siempre me he sentido como heterodoxo en razón a esta línea más, de estos teólogos. Quizás como mi meta ha sido siempre tratar de descu-

(39) CASTILLO, Fernando: "Los cristianos y el marxismo. un problema con historia", en Pastoral Popular... No disponemos de la fecha exacta de su publicación. Sabemos que fue escrito antes de la publicación de la Instrucción sobre algunos aspectos de la TdL de la Sagrada Congregación para la Doctrina de la FE, 6/8/84; pero fue publicado con posterioridad a] documento del Vaticano.

(40) Ibidem

(41) Un ejemplo: Roger Vekemans, jesuita, vocero del desarrollismo en Chile en los años 60, dejó el paîs tras la victoria electoral de Allende. Fundó el CEDIAL (Centro de Estudios para el Desarrollo e Integración de América Latina) en Bogotâ, donde se dedicó con esmero a la refutación de la TdL, con financiación de la CIA entre otros. Su libro: Teología de la liberación y Cristianos por el Socialismo, Bogotá, Colombia, 1976, no deja de ser una caricatura. 
brir esta, cómo decir, un cristianismo popular pero que no pasa tanto por ese proceso que al final es de unas élites que lo van radicalizando, a ese pueblo ¿no?, y al final es muy chico ese universo, que hoy día se destruyó además. Entonces, yo diría que ese circuito es muy dependiente de lo que es el socialcristianismo radicalizado, que eso son un Castillo y. Muñoz, socialcristianos radicalizados, marxistizados en un momento dado con Allende y que después, claro, y que hoy día están un poquito neutralizados. Eso siento yo" (42).

Max Salinas se sitúa en una posición crítica de la TdL chilena en su elaboración sistemática, sobre todo por el hecho de ser fruto de una élite y no partir desde la propia religiosidad del pueblo:

“(...) mi preocupación era porqué no ver el mundo desde los pobres y no desde nosotros mismos, desde nuestro pensamiento, nuestro elitismo. Esa fue siempre mi preocupación, porqué no ver, no partir desde la religión popular, desde la religiosidad popular, y desde ahí ver el mundo ¿no?" (43).

A priori esa era la intención de la TdL. Partir desde la realidad de los más pobres, y esa realidad incluye su religiosidad. ¿Qué es lo que pasa entonces?

Diego Irarrázaval, sacerdote chileno de la congregación de la Santa Cruz, nacido en 1943, teólogo especializado en religión popular, miembro de Cristianos por el Socialismo hasta 1973 en que tuvo que exiliarse a Perú, donde vive y realiza su trabajo pastoral en comunidades indígenas aymaras en Puno; miembro del Instituto de Estudios Aymaras, nos habla en su testimonio sobre esta cuestión, sobre la relación entre TdL y religiosidad popular:

"Casi todos los que nos movemos en ese campo distinguimos entre tipos de religión popular, hay muchos tipos de religión popular... Tampoco se puéde notificar la religión popular como una cosa casi autónoma, de resistencia ni de expresión totalmente libre de la gente. Hay ahí todo un proceso de dominación cultural-religiosa, sigue andando y es muy fuerte ¿no?. Entonces, sin exagerar o sin idealizar, digamos lo que es estos tipos de religión popular. Hay algunas expresiones que yo creo que son muy coherentes con una reflexión como la que se hace en TdL, coherentes en el sentido de que en algunas de estas formas, no en todas,pero en algunas formas de religión popular... o sea, la mujer, el indígena, el mestizo, el negro, el pobre, en fin, son sujetos reales, son protagonistas reales del diálogo con Dios, que es una cosa importantísima en una. TdL, el ser sujetos, ser portadores responsables de una transformación de la existencia en esta tierra y todo lo demás" (44).

Las religiones populares tienen expresiones de cautiverio ideológico y cultural, pero también tienen expresiones de liberación. Hay que saber dialogat con ellas para no caer en el menosprecio de la religiosidad popular, actitud de cierto

(42) SALINAS, Maximiliano: Testimonio oral, 16/11/93, Santiago, Chile.

(43) Ibidem.

(44) IRARRÁZAVAL, Diego: Testimonio oral, 5/11/93, Santiago, Chile. 
cristianismo progresista de finales de los 60 , ni tampoco pensar que la religión del pueblo está en estado puro. Una tercera actitud, que rechazan tanto Max Salinas como Diego Irarrázaval, es la de aquellos que se acercan desde la institución con la intención de adoctrinar al "pueblo supersticioso" (las comillas son nuestras), o "aprovechar" lo que esa religiosidad tenga de positivo según el criterio de la institución: "iaprovechar!, iy cuántos se han aprovechado de la religiosidad popular, del centro, de la izquierda, de la derecha!" (45).

Ahora bien, el problema de la teología de la liberación en su relación con la religiosidad popular es un problema de miopía racionalista. Esto lo explica muy bien Diego Irarrázaval, quien conoció desde dentro la experiencia de la opción por el socialismo de los grupos cristianos más progresistas en la época de Allende, y quien, tras el exilio, ha conocido desde muy cerca la vivencia de comunidades aymaras en el altiplano peruano:

"Hay en teología de la liberación un obstáculo ilustrado, somos muy ilustrados en la teología de la liberación y el contexto religioso de la gente es muy simbólico, tiene una serie de ...tiene unas lógicas, digamos, tiene otra lógica como ha dicho el Cristián Parker (46), ¿no?. Pero Cristián Parker lo ha estado subrayando como otra lógica ante la modernidad, ante ciertas formas de modernidad, y también se puede decir tiene otra lógica respecto a la religión dominante o la religión hegemónica, como se le quiera llamarle. Pero yo creo que hay en la reflexión nuestra, hay un reto muy grande (...) Y hay ahí racionalidades distintas, una racionalidad simbólica, que no es que se pueda decir que lo simbólico sea antirracional..." (47).

Terminamos con una pregunta que Diego Irarrázaval hace en el inicio de un artículo suyo titulado "Repercusión de lo popular en la teología": "¿cómo el pueblo pobre está reconstruyendo la teología de la liberación?" (48).

Cuestión muy importante que conecta con la afirmación que Gustavo Gutierrez expresa en la conclusión de su libro Teología de la liberación: "Pero, en última instancia, no tendremos una auténtica teología de la liberación sino cuando los oprimidos mismos puedan alzar libremente su voz y expresarse directa y creadoramente en la sociedad y en el seno del pueblo de Dios. Cuando ellos mismos "den cuenta de la esperanza' de que son portadores. Cuando ellos sean los gestores de su propia liberación" (49).

\section{CONCLUSIÓN}

Esta breve aproximación a la teología de la liberación en Chile nos deja ver la complejidad del tema.

(45) SALINAS, Maximiliano: Testimonio oral, 16/11/93, Santiago, Chile.

(46) Cristián Parker es un sociólogo chileno.

(47) IRARRAZAVAL, Diego: Tesimonio oral, 5/11/93, Santiago, Chile.

(48) IRARRAZAVAL, Diego: "Repercusión de lo popular en la teologia", en Cambio social y pensamiento cristiano en América Latina, de José Comblin, José I. González Faus y Jon Sobrino (editores), Madrid, 1993.

(49) GUTIERREZ, G: Teología de la liberación. Perspectivas, Salamanca, 1972, pág. 387. 
En nuestra tesis doctoral queremos construir su historia a partir de los procesos históricos a los que ha estado vinculada desde su gestación, porque, como decíamos al principio, no podemos hacer la historia de la Iglesia en Chile en estos últimos 25 años sin aludir a la teología latinoamericana de la liberación; ni tampoco podemos hacer la historia de la teología de la liberación sólo a partir del estudio de los teólogos más representativos (las palabras de Gustavo Gutierrez que hemos citado son muy claras y tajantes al respecto).

Sólo un estudio global puede acercarnos a la realidad, superando las visiones polarizadas que mitifican o caricaturizan la teología de la liberación. Ni mito ni caricatura: nuestra opción es reconstruir su historia, tomando el testimonio oral como fuente primordial y situándonos en la periferia de la historia oficial de la Iglesia, que normalmente sólo es construida a partir de lo que hacen y dicen los obispos y quienes "trabajan" al interior de la institución oficial. Hay otras voces, otros hechos, tanto o más importantes, que nos permiten "hacer" la historia de la Iglesia con mayor fidelidad a la realidad.

\section{FUENTES}

-AGUILERA, José: Testimonio oral, 15/11/93, Santiago, Chile.

-ALDUNATE, José: Testimonio oral, 25/11/93, Santiago, Chile.

-ESCOBAR, Jaime: Testimonio oral, 21/11/93, Santiago, Chile.

-GALILEA, Segundo: Testimonio oral, 24/11/93, Santiago, Chile.

-IRARRÁZAVAL, Diego: Testimonio oral, 5/11/93, Santiago, Chile.

-MORALES, Francisca: Testimonio oral, 4/12/93, Santiago, Chile.

-MUÑOZ, Ronaldo: Testimonio oral, 1/12/93, Santiago, Chile.

-ROSALES, Raúl: Testimonio oral, 16/11/93, Santiago, Chile.

-SALINAS, Maximiliano; Testimonio oral, 16/11/93, Santiago,Chile.

\section{BIBLIOGRAFIA}

CASTILLO, J.Mㄹ. ; El seguimiento de Jesús, Salamanca, 1992.

COMBLIN,J., GLEZ FAUS,J.I. y SOBRINOJ. (editores); Cambio social y pensamiento cristiano en América Latina, Madrid, 1993.

DUSSEL, Enrique: "¿Teología del laicado", en "Hacia una nueva teología del laicado", Fe y Secularidad no63, ECO, Santiago, Chile, 1988.

DUSSEL, E.: De Medellín a Puebla. Una década de sangre y esperanza. 1968-1979, México, 1979.

DUSSEL, E.: Historia general de la Iglesia en América Latina. Tomo I: Introducción general, Salamanca, 1983.

ELLACURIA, I. y SOBRINO, J. (coord.): Mysterium Liberationis. Conceptos fundamentales de la Teología de la Liberación, Madrid, 1990.

GALILEA, S.: La Teología de la Liberación después de Puebla, Bogotá, Colombia, 1979.

GIBELLINI, R. (editor): La nueva frontera de la teologia en América Latina, Salamanca, 1977.

GIRARDI, G.: El templo condena el Evangelio. El conflicto sobre la teologia de la liberación entre el Vaticano y la CLAR, Madrid, 1994.

GUTIERREZ, G.: Teología de la liberación. Perspectivas, Salamanca, 1972.

INSTITUTO FE Y SECULARIDAD: Fe cristiana y cambio social en América Latina, Salamanca, 1973. 
LIBANIO, J.B.: Teologia de la liberación. Guía didáctica para su estudio, Santander, 1989.

MUÑOZ, R.: Nueva conciencia de la iglesia en América Latina, Salamanca, 1974.

MUÑOZ, R.: Dios de los cristianos, Madrid, 1987.

PASTOR, Aníbal y otros: De Lonquén a los Andes. 20 años de Iglesia católica cbilena, Santiago, Chile, 1993.

RICHARD, P.; Cristianos por el socialismo. Historia y documentación, Salamanca, 1976.

ROSALES, R. y DE FERARI, J.M. (editores): Breve Diccionario Teológico Latinoamericano, Santiago, Chile, 1992.

TAMAYO, J.J.: Para comprender la teología de la liberación. Estella, 1990. 